A Theory on Reports of Constructive (real) and Illusory Posttraumatic Growth

Michaela Boerner, University of Nottingham, School of Education

Stephen Joseph, University of Nottingham, School of Education

David Murphy, University of Nottingham, School of Education

Corresponding author (Michaela Boerner, University of Nottingham, School of Education, Wollaton Road, Nottingham NG8 1BB, United Kingdom) 


\title{
A Theory of Reports of Constructive (real) and Illusory Posttraumatic Growth
}

\begin{abstract}
It has been suggested that self-reported posttraumatic growth could sometimes be considered as a way for people to protect themselves from the distress of trauma. In this case, reports of posttraumatic growth could be illusory. We suggest a theory on self-reported constructive (real) posttraumatic growth and illusory posttraumatic growth by using Rogers's (1959) theory and the work by Vaillant (1995). Through this theoretical framework we attempt to explain when reports of posttraumatic growth are likely to be constructive and real and when such reports are likely to represent aspects of illusions. We will also consider the implications for research practice.
\end{abstract}




\section{Theory of Reports of Constructive (real) and Illusory Posttraumatic Growth}

Trauma and adversity may cause a person to develop social and psychological difficulties including posttraumatic stress (e.g. Horowitz, Markman, Stinson, Fridhandler \& Grannam, 1995, Janoff-Bulman, 1992; Joseph, Murphy \& Regel, 2012; Rachman, 2001; van der Kolk \& McFarlane, 2007; van der Kolk, 2007). While not negating this risk to well-being, many affected people also report having gained something valuable through their struggle with a traumatic event (e.g. Janoff-Bulman, 2009; Joseph \& Butler, 2010; Solomon \& Dekel, 2007; Tedeschi \& Calhoun, 2004). The psychological benefits gained through the struggle with trauma are termed by Tedeschi and Calhoun (2004) posttraumatic growth. Tedeschi and Calhoun (2004) identified five domains of posttraumatic growth, namely: personal strength, new possibilities, relating to others, appreciation of life and spiritual change. Thus, trauma can be viewed not only as a precursor for psychological maladaption but also as a springboard towards growth (Joseph, 2011). This does not mean that trauma is in any way desirable, however, posttraumatic growth acknowledges the growth-oriented potential of people (Joseph, 2004; Joseph \& Linley, 2005).

Nevertheless, several researchers have doubted the validity of self-reported posttraumatic growth (e.g. Cheng et al., 2006; Davis \& McKearney, 2003; Frazier et al., 2009; Frazier \& Kaler, 2006; Hall, Hobfoll, Canetti, Johnson \& Galea, 2009; Hobfoll et al., 2007; McFarland \& Buehler, 2012; McFarland \& Alvaro, 2000; Wortman, 2004; Yanez, Stanton, Hoyt, Tennen \& Lechner, 2011; Zoellner \& Maercker, 2006). Most of these researchers do not question the existence of posttraumatic growth but the validity of selfreported posttraumatic growth. In other words, it is still not clear whether self-report questionnaires assessing posttraumatic growth do indeed capture actual posttraumatic growth. It has been argued that constructive (real) posttraumatic growth may not necessarily be the same as reports of posttraumatic growth (e.g. Frazier et al., 2009; Jayawickreme \& Blackie, 
2014; Maercker \& Zoellner, 2004).

Self-reports of posttraumatic growth may reflect two different constructs, namely, constructive (real) posttraumatic growth and illusory reports of posttraumatic growth. Such skeptical views towards reports of posttraumatic growth and its measurement are likely based on inconclusive results. For example, Frazier and colleagues (2009) and Yanez and colleagues (2011) suggested within a prospective study design that actual (real) posttraumatic growth may be a different construct than self-reported posttraumatic growth. In addition, research findings do not coherently show that reports of posttraumatic growth are associated negatively with posttraumatic stress (e.g. Zoellner \& Maercker, 2006; Pat-Horenczyk, Perry, HamamaRaz, Ziv, Schramm-Yavin \& Stemmer, 2015).

Some authors suggested that reports of posttraumatic growth are sometimes illusory (e.g. Gunty et al., 2011; Frazier et al., 2009; Taylor \& Brown, 1988; Taylor, 1983; Yanez et al., 2011; Zoellner \& Maercker, 2006; Zoellner, Rabe, Karl \& Maercker, 2008; Wortman, 2004). However, several researchers (e.g. Taylor \& Brown, 1988; Taylor, 1983) consider illusions of posttraumatic growth, although not real, as mainly adaptive ways of coping through which a person gathers the strength needed to face the struggle with adversity. Other authors suggested that sometimes reports of posttraumatic growth are defensive in nature (e.g. Davis \& McKearney, 2003; Hall, Hobfoll, Canetti, Johnson \& Galea, 2009; Hobfoll et al., 2007; McFarland \& Buehler, 2012). Here, potentially illusory reports of posttraumatic growth may be indicative of increased defensiveness where the affected person attempts to protect their self-structure against a mortality threat. Zoellner and Maercker $(2006,2009)$ put forward a comprehensive theory on constructive (real) posttraumatic growth and illusory posttraumatic growth. They argued that reports of posttraumatic growth may consist of two co-existent sides (“Janus-Face Theory"). They suggested that one side of posttraumatic 
growth may be real and constructive while the other side of posttraumatic growth may be a positive illusion based on Taylor (1983) and/or defensive denial.

The theory by Zoellner and Maercker $(2006,2009)$ still leaves room for some unanswered questions and for some unconsidered perspectives. For example, how is it possible in research to differentiate between constructive (real) posttraumatic growth and illusory reports of posttraumatic growth? Does constructive (real) posttraumatic growth automatically exclude experiences of distress as well as posttraumatic stress? How does a theory of constructive (real) posttraumatic growth and illusory posttraumatic growth fit within the wider field of trauma research? In short, is it possible to develop a theory on constructive (real) posttraumatic growth and illusory reports of posttraumatic growth without losing sight for the potential of every human to grow and without resorting to a medical point of view? Within the remaining sections, we attempt to answer the above questions.

In order to achieve that aim we try to synthesize a Rogerian view on defenses (1959) and personal development with the work by Vaillant (1995). Both theories may be equally important in order to explain constructive (real) posttraumatic growth and illusory reports of posttraumatic growth. At the first glance, both theories may appear mutually exclusive but we hope to show that those differences are related to the perspective taken and often about nomenclature. But before we attempt a theoretical synthesis we will discuss their view on defenses and personal development or constructive (real) posttraumatic growth respectively.

\section{Defensiveness and Reports of Posttraumatic Growth after Rogers (1959)}

Posttraumatic growth is of particular relevance to humanistic, person-centered and experiential therapies because of its recognition of positive functioning in addition to distressing experiences in adjusting to traumatic events. It is familiar idea to person-centered 
experiential therapists that people find more resilient ways of being emergent from the breakdown and disorganization of the self-structure (Joseph, 2004, Joseph \& Linley, 2005).

\section{Defensive Processes}

Rogers (1959) proposed that the organism has an inner drive to actualize its potential. This inner drive is termed the actualizing tendency that is "(...) the inherent tendency of the organism to develop all its capacities in ways which serve to maintain and enhance the organism" (Rogers 1959, p.196). Rogers (1959) also states that the actualizing tendency of the organism is by its very nature pro-social. The actualizing tendency extends towards the selfstructure as soon as a self-structure has been developed. This extension of the actualizing tendency is termed by Rogers as self-actualization. Although the self-structure develops initially in early childhood it evolves throughout life.

The self-structure is a coherent self-perception that results from experiences or clusters of experiences that were and are to some extent related to oneself (Rogers, 1959). The selfstructure is built through experiences and usually especially through experiences with other people (ibid). If the self-structure is coherent with the experiences of the organism the person moves towards the ideal of a fully functioning person (optimal psychological adjustment) (Rogers, 1959, Joseph, 2004). However, sometimes the self-structure is not coherent with organismic experience because the person has developed conditions of worth (Rogers, 2004). "Conditions of worth are those messages we introject from society and those around us about how we should behave if we are to be accepted and valued" (Joseph 2004, p.104).

Consequently, the self-actualizing tendency may work against the actualizing tendency if an individual has developed conditions of worth. In this case, experiences that threaten the self-structure may be denied or distorted in order to maintain the self-structure despite contradicting experience (Rogers, 1959). In other words, a person who has conditions of 
worth attempts to actualize a self-structure that is out of touch with the organism's actualizing tendency and with certain aspect of reality (Rogers, 1959).

\section{A Theory on Reports of Posttraumatic Growth based on Rogers}

Although Rogers (1959) never mentioned posttraumatic growth, Joseph (2004) developed a theory of constructive (real) posttraumatic growth based on Rogers's theory. He argued that if a person is affected by a traumatic event the concept of constructive posttraumatic growth and its development resembles the concept of moving towards a fully functioning person. Joseph (2004) suggested that most people hold some distortions within their self-concept. Such distortions/illusions within the self-structure are comparable to Janoff-Bulman's (1992) concept of fundamental assumptions.

Through a trauma some previously distorted experiences within the self-structure may become obvious (Joseph, 2004). For example, one could painfully recognize that life is not certain and one is more vulnerable than one would have thought (Joseph, 2004; cf. JanoffBulman, 1992). Following a trauma and a breakdown of the self-structure, people usually attempt to integrate the adverse experience (Joseph \& Linley, 2005; Joseph, 2004). This integration process (completion tendency) is often characterized by intrusive and avoidant states as in posttraumatic stress (Horowitz, 1986; Horowitz et al., 1995).

Joseph and Linley (2005) and Joseph (2004) proposed that this integration process may reflect an intrinsic need of a person to accommodate their experience. In other words, intrusive and avoidant states (posttraumatic stress) may reflect the efforts of a person to develop their self-structure in accordance with their experience. Intrusive and avoidant states may be present until a person has processed the trauma (Horowitz, 1986; Horowitz et al., 1995) or, respectively, until a person has changed their self-structure in accordance with their experience (Joseph, 2004). This change is a move towards a fully functioning person and may 
be in case of a traumatic event conceptualized as constructive (real) posttraumatic growth (ibid).

However, it should be borne in mind that the integration of a traumatic event is a process and that some parts of the traumatic event could be successfully integrated while other parts of the traumatic event still need to be processed (Joseph, 2011; Joseph \& Linley, 2008a). Therefore, it may sometimes be possible to experience constructive (real) posttraumatic growth while experiencing posttraumatic stress (Joseph, 2011). Openness to experience is one condition that Rogers (1959) identified in order for the self-structure to become more congruent with organismic experience. Using the latter assumption by Rogers (1959), one would expect a person to be lower in defensiveness when they report constructive (real) posttraumatic growth.

As mentioned, self-reports of posttraumatic growth may not necessarily reflect the constructive (real) growth process. Sometimes such reports of perceived growth may represent the attempt to ward off the pain and threat accompanied by changed inner or outer reality (e.g. Davis \& McKearney, 2003; Hall, Hobfoll et al., 2009). If so, defensive processes may be used to support well-being and self-esteem without having integrated the adverse event in a revised self-structure. The risk of this process may be that a person becomes continuously more rigid and inauthentic (Joseph, 2011; Joseph \& Linley, 2008a; Joseph \& Linley, 2006).

\section{What does Rogers Theory not explain?}

Although Rogers is specific about the maladaptive effect of defenses concerning the actualizing tendency, his conceptualization of defenses is not very differentiated. Through Rogers's theory, we are able to explain why defensive operations could be used when illusory posttraumatic growth is reported but not what kind of defenses could be used. Moreover, Rogers (1959) argues that moving towards "the fully functioning person" and therefore 
constructive (real) posttraumatic growth is only possible when the person is open to experience. In other words, the person needs to be low in defensiveness in order to experience constructive (real) posttraumatic growth. However, Rogers $(1959,1971)$ also argued that being low on defensiveness is only possible when some fundamental needs are met as, for example, unconditional positive regard, empathy, freedom of choice and reduction of threat. These fundamental needs are unfortunately not always met. By incorporating Vaillant's theory (1995) on defensiveness, we will argue that although such positive conditions are essential it may be sometimes possible to develop constructive (real) posttraumatic growth whilst several needs remain unmet. Before we attempt to synthesize both theories we will discuss Vaillant's (1995) view on defensiveness and personal development.

\section{Defensiveness and Reports of Posttraumatic Growth after Vaillant (1995)}

Vaillant (1995) approaches his theory from a psychoanalytical angle. Although this appears to be in contrast to the theory of Rogers we argue that this is not necessarily the case. Vaillant (1995) highlights, like Rogers, the positive potential of human beings and their capacity to develop and grow.

\section{Defensive Processes}

Although Vaillant approaches the concept of human development from a psychoanalytical view he does not work with a traditional Freudian framework. Within Vaillant's theory, the integrity of the ego plays a decisive role. The term "ego" is used as a metaphor for the capacity of the human to integrate experiences (Vaillant, 1995). We could also substitute the term ego with the term integration system. The ego or the integration system is needed to accommodate experience within a revised self-structure or to assimilate experience (Vaillant, 1995). The ego could be threatened when a sudden change emerges 
within four areas, namely, conscience, people, desire (affect) or reality. According to Vaillant (1995) the emergence of abrupt change in one of the four areas may have the potential to create a conflict. The ego may use defensive operations if this conflict cannot be borne.

Vaillant (1995) differentiates between adaptive and long-term maladaptive defenses (e.g. neurotic and immature defenses). Mature defenses allow for the experience of internal and external reality although in an attenuated manner (Vaillant, 1995). Mature defenses also allow us to integrate/accommodate experience. Maladaptive defenses, in contrast, change either internal or external reality or both (Vaillant, 1995). In the case of long-term maladaptive defenses, experience is not integrated/accommodated but is instead warded off.

\section{A Theory on Reports of Posttraumatic Growth on the basis of Vaillant's Theory}

Like Rogers (1959) Vaillant (1995) does not discuss posttraumatic growth within his theory. However, he developed a growth-oriented theory that may be capable of explaining the development of self-reported constructive (real) and illusory posttraumatic growth. The experience of a trauma may constitute an abrupt change in at least one of the following areas, namely, consciousness, desire (affect), people (relationships) and reality. Vaillant (1995) argues that defensive operations may be used when the conflict caused by the sudden change cannot be borne.

It may be likely that constructive (real) posttraumatic growth develops when low levels of defensiveness are used and when the conflict and stress can be endured. When the conflict and stress cannot be borne constructive (real) posttraumatic growth may be, nevertheless, more likely to occur when higher levels of mature defenses are used. The reason for our assumption is that mature defences mainly allow the user to experience internal and external reality although in an attenuated manner (Vaillant, 1995). Hence, experiences may become integrated (Vaillant, 1995). 
Vaillant (1995) lists several mature defenses such as altruism, sublimation, suppression, anticipation and humour. To make it more plastic, we will show on an example when mature defences could emerge. Following a trauma, the reality and the affect of person may have been suddenly changed. Several researchers such as Tedeschi and Calhoun (2004) emphasize the crucial role of disclosure and social support in order to make sense of the experience. However, disclosure bears the risk to be blocked, rejected and blamed by the social environment (e.g. Wortman, 2004). Wortman (2004) describes several circumstances where empathic listening and unconditional regard is rather an exception than a normal response towards trauma survivors. Here, disclosure may not lead to social support but to further hurt. In case the resulting pain cannot be borne, mature defenses could have the potential to sustain social support and to integrate at the same time the traumatic experience. In this way, the development of constructive (real) posttraumatic growth may be facilitated. For example, sublimation generally channels affects, ideas and thoughts into cultural places where they are accepted by the person who displays them and by the persons who are exposed to them. Examples for this type of trauma processing are acts on stage, songs, dances, paintings and writings that express feelings, thoughts or ideas about the trauma. The examples given do not imply that all cultural expressions revolving around the theme of trauma or suffering are a result of mature defenses but sometimes they are.

In contrast, high levels of long-term maladaptive defenses (neurotic and immature defenses) may alter or ward off internal and external reality (Vaillant, 1995). Vaillant (1995) lists several neurotic defenses such as reaction formation and repression. He also lists several immature defenses such as acting out, dissociation, passive aggression and projection. In this case, some experiences cannot be integrated. However, although constructive (real) posttraumatic growth may often not be present when high levels of long-term maladaptive defenses are used some people may, nevertheless, perceive and report posttraumatic growth. 
In this case, we assume that those reports represent primarily illusory posttraumatic growth. Here, illusory reports of posttraumatic growth could constitute a pattern of defensive processes that ward off overwhelming stress and pain.

To make it less abstract, we will illustrate using an example of when illusory posttraumatic growth could emerge. Following a trauma, the reality and the affect of person may have been suddenly changed. The person may experience negative emotions and thoughts for a longer time period. However, this change could be unacceptable for the person itself or for its social environment or both. Imagine a person who is raised to take pride in being strong and positive. The person is, furthermore, embedded in an environment that has no positive regard for "negative" emotions. In this situation, the person could use the neurotic defense mechanism of reaction formation turning, for example, sadness into gain. Here, the affected person would not feel and report the emotion of sadness but would talk about finding strength and gaining something valuable. Because the emotion of loss is not experienced, it cannot be integrated. Hence, it may be probable that in such case reports of posttraumatic growth are rather illusory. The example given does not imply that all reported positive outcomes concerning trauma by simultaneously omitting the negative side are a result of maladaptive defenses but sometimes they might be.

\section{Rogers' (1959) and Vaillant's (1995) theory: A synthesis}

\section{Similarities and Differences between the two Theories}

Before attempting to bridge Vaillant's (1995) view with a Rogerian framework, we first will highlight some differences and similarities between Rogers (1959) and Vaillant (1995). Rogers's (1959) theory is organized around the actualizing tendency of the organism. Rogers (1959) uses the construct of the actualizing tendency in order to explain why people 
are growth-oriented by their very nature. In contrast, Vaillant (1995) mainly argues from a survival perspective. However, Vaillant's theory about defensiveness does not explicitly exclude the possibility for an actualizing tendency of the organism.

The inclusion of the ego is another main difference between Rogers's and Vaillant's theory on defenses. Rogers (1959) assumes that defenses are used to sustain a self-structure while Vaillant (1995) assumes that people use defenses if their integration system (ego) is not able to deal with sudden change. Although both authors differ on their perspective of why defenses are used, the result of using defensive operations is the same. With one exemption that will be discussed later, both authors assume that defensiveness may hinder a person from changing their self or their self-structure. Within both theories, the use of defensive operations may impede personal development and constructive (real) posttraumatic growth respectively.

Rogers (1959) and Vaillant (1995) differ also concerning their specificity on defenses. Rogers (1959: 228) preferred to have a less differentiated scheme of defenses. In contrast, Vaillant (1995) specifies several long-term maladaptive defensive operations (neurotic and immature defenses) that may have the potential to hinder personal development. Although defenses may be useful in the short-term some of them may hinder change within the selfstructure. Vaillant (1995) suggested that immature defenses and neurotic defenses distort either external or internal reality. Hence, using immature defenses or neurotic defenses may hinder the accommodation of experiences or particular aspects of experiences. In other words, neurotic and immature defenses could hinder a person from changing their self-structure according to the experience. Nevertheless, the link between Vaillant (1995) and Rogers (1959) lies in seeing defensive operations as natural, organismic behaviors that are intended to integrate experience as far as is possible at a given time and to enable the person to process experience in a way that is consistent with their current available psychological and physical capacities. 
In contrast to Rogers (1959), Vaillant (1995) assumes that not all defensive operations have the potential to hinder personal development or constructive (real) posttraumatic growth respectively. Mature defenses may even allow for personal development or constructive (real) posttraumatic growth. However, we assume that Rogers (1959) may have not considered mature defenses as defenses but instead as mature constructive behavior. The reason for this claim is that mature defenses do not hinder experiences from being accurately symbolized in awareness although they may be less sharp and vivid as in instances where a person is low in defensiveness. Therefore, we assume that mature defenses after Vaillant (1995) and mature constructive behavior after Rogers (1959) are actually very similar. The main difference between the two concepts is that mature defenses are related to an adverse situation and occur without immediate reflective awareness (automatically). In other words, mature defenses are used in response to stress while mature constructive behavior after Rogers (1959) is not tied to any specific situation. In total, constructive mature behavior, that may also include mature defensiveness (in Vaillant's terms), allows the person to accommodate experience and to alter the self-structure according to experience.

\section{A Theory on Constructive (real) and Illusory Posttraumatic Growth using Rogers's (1959) and Vaillant's (1995) Frameworks}

Following trauma, one's fundamental assumptions/self-structure comes under threat and may often be shattered or disorganized respectively (Horowitz et al., 1995; JanoffBulman, 2009; Joseph, 2004; Tedeschi \& Calhoun, 2004). Through a trauma, some distortions within the self-structure may become evident (Joseph, 2004). One may painfully recognize that life is not certain and one is more vulnerable than one would have thought (Joseph, 2004; cf. Janoff-Bulman, 1992). After a traumatic event and a breakdown of the selfstructure people attempt usually to integrate the adverse experience (Joseph \& Linley, 2005; Joseph, 2004). This integration process is often characterized by intrusive and avoidant states 
(completion tendency) or posttraumatic stress respectively (Horowitz, 1986; Horowitz et al., 1995). Joseph and Linley (2005) and Joseph (2004) argue that this integration process may reflect an intrinsic need of a person to accommodate their experience. In other words, intrusive and avoidant states (posttraumatic stress) may reflect the efforts of a person to develop their self-structure in accordance with their experience.

Intrusive and avoidant states may be present until a person has processed the trauma (Horowitz, 1986; Horowitz et al., 1995) or, respectively, until a person has changed their selfstructure in accordance with their experience (Joseph, 2004). Although shattered fundamental assumptions/self-structure provides the chance to reconfigure and create a self-structure that is more congruent with experience (Joseph, 2004; Rogers, 1959), this process is highly distressing. This helps explain why several researchers found that reports of posttraumatic growth are often associated with distress (e.g. Calhoun \& Tedeschi, 2009; Dekel, Ein-Dor \& Solomon, 2012; Helgerson, Reynolds \& Tomich, 2006; Joseph, 2011; Kunz, Joseph, Greyh \& Peter, 2016; Shakespeare-Finch \& Lurie-Beck, 2014; Tedeschi \& Calhoun, 2004). Initially and paradoxically, this could indicate that the reports of growth are genuine (e.g. Cheng, Wong \& Tsang, 2006; Joseph, 2011).

We assume, furthermore, that self-reports of growth may be constructive and real when low levels of long-term maladaptive defenses (neurotic and immature defenses) are used. This assumption is made because Rogers (1959) suggested that the self-structure may not change in accordance with the experience when defensive operations are used. Selfreports of growth are likely to be constructive and real when higher levels of mature constructive behavior, that may also include mature defenses, are present. Here, the assumption is that the experience can be perceived in awareness and may, hereupon, change the self-structure.

As mentioned above, self-reports of posttraumatic growth may not necessarily reflect 
the constructive (real) growth process. Sometimes such reports of perceived growth may represent the attempt to ward off the pain and threat accompanied by changed inner or outer reality (e.g. Davis \& McKearney, 2003; Hall, Hobfoll, Canetti, Johnson \& Galea, 2009). If so, defensive processes may be used to support well-being and self-esteem without having integrated the adverse event within a revised self-structure. As such, it might be hypothesized that following a trauma, some people may use defensive operations in order to protect their current self-structure and world-view (e.g. Horowitz et al., 1995; Joseph, Murphy \& Regel, 2012; Joseph, 2011). Therefore, high levels of neurotic and immature defensiveness may hinder a person from altering their self-structure and world-views in a way congruent to their experience. We hypothesize, when people use high levels of neurotic or immature defensiveness, self-reports of posttraumatic growth may sometimes not be real but rather expressions of illusory posttraumatic growth.

\section{Research Implications}

As discussed, reports of posttraumatic growth may sometimes not reflect constructive (real) posttraumatic growth but may sometimes be illusory (e.g. Davis \& McKearney, 2003; Gunty et al., 2011; Frazier et al., 2009; Hall et al., 2009; Hobfoll et al., 2007; McFarland \& Buehler, 2012; Taylor \& Brown, 1988; Taylor, 1983; Yanez et al., 2011; Zoellner \& Maercker, 2006; Wortman, 2004). Therefore, self-reports of posttraumatic growth may perhaps not validly measure constructive (real) posttraumatic growth. We suggest, therefore, that self-reports of posttraumatic growth and constructive (real) posttraumatic growth should be considered as two separate phenomena. To measure constructive (real) posttraumatic growth it has been suggested to use a prospective study design (e.g. Frazier et al., 2009; Jayawickreme \& Blackie, 2014; Linley \& Joseph, 2008b). However, a prospective study design may often be unfeasible considering the need for high resources. Moreover, also prospective study designs 
may be prone to defensive reports of posttraumatic growth. We suggest, therefore, another way to explore self-reported constructive (real) posttraumatic growth and illusory posttraumatic growth. By investigating defensiveness along with reports of posttraumatic growth, it may be possible to explore constructive (real) posttraumatic growth and illusory posttraumatic growth separately and in more detail. We would predict that real constructive posttraumatic growth will be indicated when self-reports of growth are accompanied by low scores on neurotic and immature defensiveness.

\section{Summary}

Reports of posttraumatic growth may sometimes not reflect constructive (real) posttraumatic growth but may be illusory. We suggested a theory that may account for self-reported constructive (real) posttraumatic growth and illusory posttraumatic growth. Here, we synthesized a Rogerian view (1959) on defensive processing and growth with the work on defense styles by Vaillant (1995). The theory we suggested is also able to explain possible processes that could lead to self-reported constructive (real) posttraumatic growth and illusory posttraumatic growth. We suggested that high levels of immature and neurotic defensiveness could hinder the development of constructive (real) posttraumatic growth. In contrast, low levels of neurotic or immature defensiveness or high levels of mature defensiveness may facilitate the development of constructive (real) posttraumatic growth. In total, our theory attempts to indicate when self-reported posttraumatic growth is likely to be constructive (real) and when such reports are rather likely to be illusory. The theory proposed was also connected to the wider field of trauma research. This theory offers a way to understand the phenomenon of trauma processing following an adverse event in a way that is theoretically consistent with Rogers's (1959) theory of personality, whilst bringing it into the contemporary field of posttraumatic growth literature. 
The theory has several limitations. First, our primary focus is on defense mechanisms. However, also other factors may be relevant for the development of self-reported constructive (real) posttraumatic growth or illusory posttraumatic growth. Moreover, we only included defences that were conceptualized and discussed by Vaillant (1995); other defences and potentially other meanings have not been considered. The theory also does not explain why some people do not report posttraumatic growth and why some people report posttraumatic growth be it constructive (real) or illusory. Finally, the theory developed uses mainly a Rogerian and in some parts a contemporary psychoanalytical framework after Vaillant (1995). Therefore, its perspective is limited to those frameworks. Other theoretical frameworks may explain self-reported constructive (real) and illusory reports of posttraumatic growth in a different way by using a different perspective. 


\section{References}

Calhoun, L.G., \& Tedeschi, R.G. (2009). The foundation of posttraumatic growth: An expanded framework. In L.G. Calhoun \& R.G. Tedeschi (Eds.), Handbook of posttraumatic growth: Research and practice (pp. 3-23). New Jersey: Psychology Press.

Cheng, C., Wong, W., \& Tsang, K.W. (2006). Perception of benefits and costs during SARS: An 18months prospective study. Journal of Consulting, 74, 870-879.

Davis, C.G., \& McKearney, J.M. (2003). How do people grow from their experience with trauma or loss? Journal of Social and Clinical Psychology, 22, 477-492.

Dekel, S., Ein-Dor, T., \& Solomon, Z. (2012). Posttraumatic growth and posttraumatic distress: A longitudinal study. Psychological Trauma: Theory, Research, Practice, and Policy, 4, 94-101.

Frazier, P., Tennen, H., Gavian, M., Park, C., Tomich, P., \& Tashiro, T. (2009). Does self-reported posttraumatic growth reflect genuine positive change?. Psychological Science, 20, 912-919.

Frazier, P., \& Kaler, M.E. (2006). Assessing the validity of self-reported stress-related growth. Journal of Consulting and Clinical Psychology, 74, 859-869.

Gunty, A.L., Frazier, P.A., Tennen, H., Tomich, P., Tashiro, T., \& Park, C. (2011). Moderators of the relation between perceived and actual posttraumatic growth. Psychological Trauma: Theory, Research, Practice and Policy, 3, 61-66.

Hall, B.J., Hobfoll, S.E., Canetti, D., Johnson, R.J., \& Galea, S. (2009). The defensive nature of benefit finding during ongoing terrorism: An examination of a national sample of Israeli Jews. Journal of Social Clinical Psychology 28, 993-1021.

Helgeson, V.S., Reynolds, K.R., \& Tomich, P.L. (2006). A meta-analytic review of benefit finding and growth. Journal of Consulting and Clinical Psychology, 74, 797-816.

Hobfoll, S.E., Hall, B.J., Canetti-Nisim, D., Galea, S., Johnson, R.J., \& Palmieri, P. (2007). Refining our understanding of traumatic growth in the face of terrorism: Moving from meaning cognitions to doing what is meaningful. Applied Psychology: An International Review, 56, 345-366.

Horowitz, M.J., Markman, H.C., Stinson, C.H., Fridhandler, B., \& Grannam, J.H. (1995). A classification theory of defense. In J.L. Singer (Ed.), Repression and dissociation: Implication for personality theory, psychopathology, and health (pp. 61-84). Chicago: The University of Chicago Press.

Horowitz, M.J. (1986). Stress response syndromes. New Jersey: Aronson.

Janoff-Bulman, R. (2009). Schema-change perspectives on posttraumatic growth. In L.G. Calhoun \& R.G. Tedeschi (Eds), Handbook of posttraumatic growth: Research and practice (pp. 81-99).. New Jersey: Psychology Press.

Janoff-Bulman, R. (1992). Shattered assumptions: Towards a new psychology of trauma. New York: The Free Press. 
Jayawickreme, E., \& Blackie, L.E.R. (2014). Posttraumatic growth as positive personality change: Evidence, controversies and future directions. European Journal of Personality, 28, 312-331.

Joseph, S., Murphy, D., \& Regel, S. (2012). An affective-cognitive processing model of post-traumatic growth. Clinical Psychology and Psychotherapy. doi: 10.1002/cpp.1798.

Joseph, S. (2011). What doesn' t kill us: The new psychology of posttraumatic growth. London: Piatkus.

Joseph, S., \& Butler, L.D. (2010). Positive changes following adversity. PTSD Research Quarterly 21, 1-8. Retrieved from http://www.psychologytoday.com/files/attachments/75676/positivechanges-following-adversity.pdf.

Joseph, S., \& Linley, P.A. (2008a). Positive psychological perspectives on posttraumatic stress: An integrative psychosocial framework. In S. Joseph, \& P.A. Linley (Eds.), Trauma, recovery, and growth: Positive psychological perspectives on posttraumatic stress (pp. 3-20). New Jersey: John Wiley \& Sons.

Joseph, S. \& Linley, P. A. (2008b). Psychological assessment of growth following adversity: A review. In S. Joseph, \& P. A. Linley, (Eds.). Trauma, recovery, and growth: Positive psychological perspectives on posttraumatic stress. (pp. 21-38). Hoboken, NJ: John Wiley \& Sons, Inc.

Joseph, S., \& Linley, P.A. (2006). Positive therapy: A meta-theory for positive psychological practice. East Sussex: Routledge.

Joseph, S., \& Linley, P.A. (2005). Positive adjustment to threatening events: An organismic valuing theory of growth through adversity. Review of General Psychology, 9, 262-280.

Joseph, S. (2004). Client-centred therapy, post-traumatic stress disorder and post-traumatic growth: Theoretical perspectives and practical implications. Psychology and Psychotherapy, 77, 101119.

Kunz, S., Joseph, S., Geyh, S., \& Peter, C. (2016) Posttraumatic growth and adjustment to spinal cord injury: moderated by posttraumatic depreciation? Psychological Trauma: Theory, Research, Practice, and Policy, doi: org/10.1037/tra0000164.

Maercker, A., \& Zoellner, T. (2004). The Janus face of self-perceived growth: Toward a twocomponent model of posttraumatic growth. Psychological Inquiry, 15, 41-48.

McFarland, C., \& Buehler, R. (2012). Negative moods and the motivated remembering of past selves: The role of implicit theories of personal stability. Journal of Personality and Social Psychology, 102, 242-263.

McFarland, C., \& Alvaro, C. (2000). The impact of motivation on temporal comparisons: Coping with traumatic events by perceiving personal growth. Journal of Personality and Social Psychology, 79, 327-343. 
Pat-Horenczyk, R., Perry, S., Hamama-Raz, Y., Ziv, Y., Schramm-Yavin, S., \& Stemmer, S.M. (2015). Posttraumatic growth in breast cancer survivors: Constructive and illusory aspects. Journal of Traumatic Stress, 28, 214-222.

Rachman, S. (2001). Emotional processing, with special reference to post-traumatic stress disorder. International Review of Psychiatry, 13, 164-171.

Rogers, C.R. (1971). On becoming a person: A therapist's view of psychotherapy. London: Constable \& Company Ltd.

Rogers, C.R. (1959). A theory of therapy, personality, and interpersonal relationships, as developed in the client-centered framework. In S. Koch (Ed.), Psychology: A study of a science (pp. 184256). New York: McGraw-Hill.

Shakespeare-Finch, J., \& Lurie-Beck, J. (2014). A meta-analytic clarification of the relationship between posttraumatic growth and symptoms of posttraumatic distress disorder. Journal of Anxiety Disorders, 28, 223-229.

Solomon, Z., \& Dekel, R. (2007). Posttraumatic stress disorder and posttraumatic growth among Israeli ex-POW' s. Journal of traumatic Stress, 20, 303-312.

Taylor, S. (1983). Adjustment to threatening events: A theory of cognitive adaption. American Psychologist, 38, 1161-1173.

Taylor, S.E., \& Brown, J.D. (1988). Illusion and well-being: A social psychological perspective on mental health. Psychological Bulletin, 103, 193-210.

Tedeschi, R.G., \& Calhoun, L.G. (2004). Posttraumatic growth: Conceptual foundations and empirical evidence. Psychological Inquiry, 15, 1-18. Retrieved from http://data.psych.udel.edu/abelcher/Shared\%20Documents/3\%20Psychopathology\%20(27)/Te deschi,\%20Calhoun,\%202004.pdf.

Vaillant, G.E. (1995). The wisdom of the ego. United States of America: Harvard University Press.

Van der Kolk, B.A. (2007). The complexity of adaption to trauma: Self-Regulation, stimulus discrimination, and characterological development. In B.A. Van der Kolk, A.C. McFarlane \& L. Weisaeth (Eds), Traumatic stress: The effects of overwhelming experience on mind, body, and society (pp. 182-213). New York: Guilford Press.

Van der Kolk, B.A., \& McFarlane, A.C. (2007). The black hole of trauma. In . In B.A. Van der Kolk, A.C. McFarlane \& L. Weisaeth (Eds) Traumatic stress: The effects of overwhelming experience on mind, body, and society (pp. 3-23). New York: Guilford Press.

Wortman, C.B. (2004). Posttraumatic growth: Progress and problem. Psychological Inquiry, 15, 8190.

Yanez, B.R., Stanton, A.L., Hoyt, M.A., Tennen, H., \& Lechner, S. (2011). Understanding perceptions of benefit following adversity: How do distinct assessments of growth relate to coping and adjustment to stressful events? Journal of Social and Clinical Psychology, 30, 699-721. 
Zoellner, T., \& Maercker, A. (2009). Posttraumatic growth and psychotherapy. In L.G. Calhoun, \& R.G. Tedeschi (Eds.), Handbook of posttraumatic growth: Research and practice (pp. 334354). New Jersey: Psychology Press.

Zoellner, T., Rabe, S., Karl, A. \& Maercker, A. (2008). Posttraumatic growth in accident survivors: openness and optimism as predictors of its constructive or illusory sides. Journal of Clinical Psychology, 64, 245-263.

Zoellner, T., \& Maercker, A. (2006). Posttraumatic growth in clinical psychology - A critical review and introduction of a two component model. Clinical Psychology Review, 26, 626-653. 